\title{
PROBLEMAS DE HISTORIA DEL TIEMPO PRESENTE: VIOLENCIA POLÍTICA, OPINIÓN PÚBLICA Y PRENSA EN MÉXICO EN LOS AÑOS SETENTA.
}

\author{
Sergio Arturo Sánchez Parra ${ }^{1}$ \\ https://orcid.org/0000-0001-9036-1464 \\ Anderson Paul Gil Pérez ${ }^{2}$ \\ https://orcid.org/0000-0002-9741-4220
}

\section{RESUMEN}

Recebido: 25.06 .2020

El objetivo es analizar el proceso de construcción de opinión pública sobre la violencia política en México en los inicios de la década de 1970. El tipo de metodología que se utiliza es principalmente cualitativo con apoyo en el método histórico-crítico y la revisión por coyunturas de fuentes documentales de prensa, en particular de El Sol de Sinaloa, diario perteneciente a la Cadena García Valseca. Para desarrollar el objetivo se despliegan tres momentos. El primero, tiene que ver con la exploración de los problemas de Violencia Política (Aróstegui, 1996) y Opinión Pública (Habermas, 1985; Noelle-Neumann 1995) en una perspectiva de Historia del Tiempo Presente; el segundo, refiere a la revisión del contexto de la violencia política en México a comienzos de la década de 1970, observando las tendencias en los discursos publicados en la prensa para influir en la opinión pública; para avanzar en un tercer momento de conclusión donde se proponen algunas recurrencias entre pasado y presente.

Palabras Clave: Violencia Política; Opinión Pública; Historia del Tiempo Presente; Historia de México.

Problemas da história do tempo presente: Violência politica, opinião pública e imprensa no México nos anos setenta. RESUMO

O objectivo é analisar o processo de construção da opinião pública sobre a violência política no México no início dos anos 1970. A metodologia utilizada é predominantemente qualitativa, apoiada no método histórico-crítico e na revisão por conjunturas de fontes documentais da imprensa, em particular do jornal El Sol de Sinaloa da Rede García Valseca. O desenvolvimento do objetivo desdobra-se em três momentos. O primeiro tem a ver com a exploração dos problemas da Violência Política (Aróstegui, 1996) e da Opinião Pública (Habermas, 1985; Noelle-Neumann 1995) em uma perspectiva da História do Tempo Presente; o segundo refere-se à revisão do contexto da violência política no México no início dos anos 1970, observando as tendências dos discursos veiculados na imprensa para influenciar a opinião pública; o terceiro momento é de conclusão onde se propõem algumas recorrências entre o passado e o presente.

Palavras-Chave: Violência Política; Opinião pública; História do Tempo Presente; História do México.

Problems of the History of Present Time: Political violence, public opinion and the press in Mexico in the 1970s.

\section{ABSTRACT}

The objective is to analyze the process of construction of public opinion on political violence in Mexico in the early 1970s. The type of methodology used is mainly qualitative, supported by the historical-critical method and the review by conjunctures of documentary press sources, in particular from the newspaper El Sol de Sinaloa belonging to the García Valseca Chain. To develop the objective three moments unfold. The first has to do with the exploration of the problems of Political Violence (Aróstegui, 1996) and Public Opinion (Habermas, 1985; Noelle-Neumann 1995) from a perspective of Present Time History; the second refers to the review of the context of political violence in Mexico at the beginning of the 1970s, observing the tendencies in the speeches published in the press to influence public opinion; to advance in a third moment of conclusion where some recurrences between past and present are proposed.

Key Words: Political Violence; Public opinion; History of the Present Time; Mexico history.

${ }^{1}$ Universidad Autónoma de Sinaloa. Correo electrónico ssanchez_parra@uas.edu.mx

${ }^{2}$ Universidad Autónoma de Sinaloa. Correo electrónico anderson.gil@uas.edu.mx 


\section{Introducción}

Las Ciencias Sociales y Humanas tienen un papel importante en la explicación de los problemas de violencia política y en la forma cómo se transmiten por los medios de comunicación. Los fenómenos de opinión pública requieren ser abordados desde los cruces fronterizos que permiten disciplinas como la Sociología, la Comunicación y la Historia. La prensa política se constituye como uno de los ámbitos formales que son generadores de opinión pública en la manera cómo aborda los problemas relacionados con el poder (Habermas, 1985), las dinámicas entre actores sociales, la promoción o el linchamiento mediático a las formas de acción colectiva, la representación de las organizaciones guerrilleras, y en general, las características de la violencia política (Gamiño, 2011; Uribe y Ureña, 2019).

La mayoría de los estudios sobre la relación entre prensa y poder señalan la importancia que tienen los medios al momento de gestionar la esfera pública y en la promoción de las ideas legitimadoras acerca de las dinámicas gubernamentales e institucionales del poder, el sistema político, la cultura política y la sociedad civil (Borrat, 1989; Castells, 2009; Fontcuberta y Borrat, 2006). La coincidencia se extiende a la idea de considerar el carácter histórico de la influencia entre prensa y poder en la formación de la opinión pública, siendo tan diversas las formas como las épocas en que dicha relación entra en juego en la dinámica política, pero entendiendo que la comprensión de estos procesos en el pasado histórico particular es lo que permite establecer rutas de análisis para los complejos presentes.

En el caso de México durante los años sesenta y setenta del siglo XX la prensa se inscribió en las dinámicas ideológicas de la Guerra Fría. Las visiones y representaciones construidas por la prensa mexicana frente al acontecer político, ideológico y militar latinoamericano fueron puestas en relación con inquietudes nacionales y locales (Pettinà, 2018; Rivas, 2014; Sánchez, 2016; Serna, 2014; Vásquez, 2012). Es importante explicar las diversas aristas que generó en los periódicos la existencia de organizaciones armadas que en diversos momentos realizaron acciones políticas y militares en las regiones del país. Al mismo tiempo, preguntar bajo qué condicionantes los medios de comunicación dieron una cobertura particular al fenómeno de la violencia política. Lo que en esencia tiene como correlato la historia de las relaciones entre gobiernos, medios de comunicación y poder político, para generar un engranaje que permite explicar las maneras en que se cubrieron los problemas políticos de toda índole (Gamiño, 2011; Sánchez, 2016).

Desde el campo de la Historia del Tiempo Presente se puede aportar a la comprensión de los procesos políticos y sociales que México comenzó a vivir hace cinco décadas durante los gobiernos de Gustavo Díaz Ordaz (1964-1970) y Luis Echeverría Álvarez (1970-1976), alrededor de la tensión entre orden estatal y demandas sociales, entre emergencia de nuevos actores y hegemonía de actores políticos tradicionales, y entre la necesidad de mayor participación política y restricciones democráticas. Cabe señalar que los problemas de Historia del Tiempo Presente se encuentran implicados en la construcción de las memorias sobre el pasado: memorias públicas, oficiales, alternativas, de resistencia, hegemónicas, etc. (Allier, 2018; Fazio, 2018).

Buscar una explicación histórica, de acuerdo con Georges Duby (1988), implica fortalecer las herramientas analíticas e interpretativas que facilitan comprender las preguntas del comportamiento de un fenómeno. En este caso se trata de revisar la prensa nacional en los años setenta del siglo XX, para detenerse en el análisis de su postura frente a las organizaciones que representaron la oposición al régimen político. El papel deontológico de la historia no puede ser otro que apropiarse del pasado para deconstruir mediante preguntas y respuestas la complejidad del presente. Frente a esto, Marc Bloch fue insistente en que la Historia busca explicar a los hombres en el tiempo, pero no sólo en el pasado sino también en la actualidad, y Michel De 
Certeau advirtió que se debe mantener una relación enigmática entre el pasado y el presente, a través de las fuentes y los lentes teóricos para trabajar con ellas ${ }^{3}$.

En este marco se ubica el presente artículo, en el que se analiza el pasado-presente mediante la revisión del proceso de construcción de opinión pública sobre la violencia política en México en los inicios de la década de 1970. El tipo de metodología que se utiliza es, principalmente, cualitativa con apoyo en el método histórico-crítico y la revisión por coyunturas de fuentes documentales de prensa, en particular El Sol de Sinaloa diario perteneciente a la Cadena García Valseca, entre 1970 y 1974 con un total de 515 registros divididos por año de la siguiente manera: 80 (1970), 94 (1971), 141 (1972), 87 (1973), 113 (1974). Los principales tipos periodísticos consultados fueron las editoriales, los artículos con y sin autor, los desplegados, los epígrafes y los telegramas. Se optó por un análisis de discurso interpretativo a partir de las variables posición editorial frente a la violencia, cobertura de los hechos violentos, imágenes de los actores y organizaciones sociales.

El artículo se desarrolla en dos momentos. En el primero, se revisan los problemas de violencia política y opinión pública en una perspectiva de Historia del Tiempo Presente. En el segundo, se presenta el contexto de la violencia política que vivió México a comienzos de la década de 1970, para observar tendencias en los discursos publicados en la prensa política para influir en la opinión pública. Por último, se concluye la necesidad de fortalecer la indagación de este tipo de problemas desde la relación Historia y Ciencias Sociales.

\section{Violencia política, opinión pública e Historia del Tiempo Presente}

La violencia política revela la existencia de conflictos por el poder político y por el funcionamiento del Estado. Julio Aróstegui concuerda en que el sentido de la violencia política como categoría del análisis histórico se centran en las posibilidades que ofrece para entender que el proceso evolutivo humano está mediado por conflictos, los cuales pueden ser estudiados a partir de una revisión contextual y profunda del marco temporal y temático en el que ocurren los fenómenos, con el fin de no caer en los peligrosos anacronismos de considerar la violencia en un sentido general, o de asumir por formas y dinámicas de violencia comportamientos presentes que no significaban lo mismo en el pasado (Aróstegui, 1996, p. 9).

Conviene evadir la violencia política en genérico porque dificulta "determinar con claridad qué debe incluirse y qué excluirse de una reconstrucción histórica" (Aróstegui, 1996, p. 17). La violencia política se entiende como la tensión permanente entre gobernantes y gobernados, pero que asume varias formas (Aróstegui, 1996, p. 18). Con un argumento cercano, Jaime Talancón considera que la violencia política se encarga de articular la relación entre:

a) Gobernados y gobernantes (rebelión, asonada, insurrección, revolución); b) Gobernantes y gobernados (represión, persecución, tortura, dictadura); c) Gobernados y gobernados (guerra civil); d) Gobernantes y gobernantes: I) Conflicto interno (golpe de Estado, magnicidio, asesinato político), II) conflicto externo (entre líderes o Jefes de Estado [guerra]) (Talancón, 2009, p. 377).

Lo que se observa es que la violencia política implica mirar relaciones que se articulan mediante tensiones recurrentes. Como cuando un gobierno intenta imponer el orden en sus calles a costa de reprimir a los manifestantes, o como cuando estos manifestantes transgreden edificios gubernamentales y comerciales para lograr que el eco de su voz resuene en los medios de comunicación oficiales, o bien cuando un partido político convoca a una movilización por mayor libertad y participación política y el partido político que gobierna prohíbe la manifestación derivando en una guerra civil, etc. En cada caso, son las relaciones de poder dentro de los Estados las que están en ebullición, las que puestas en escena buscan un orificio de escape, una manera de distención, una solución al conflicto (Aróstegui, et al, 2000; Talancón, 2009). En este contexto,

\footnotetext{
${ }^{3}$ En este sentido, la Historia establece un diálogo recurrente con las demás Ciencias Sociales, no se trata de una disciplina que se aísle en sus propias fronteras del conocimiento. El enfoque historiográfico no parte de preguntas narrativas o parroquiales, sino de problemas contextualizados que tienen una respuesta particular a partir del uso de las fuentes primarias y secundarias, pero que reflejan procesos y comportamientos sociales que pueden ocurrir de manera similar en otros espacios y temporalidades (Braudel, 1968; Silva, 2014).
} 
son fundamentales los actores políticos y la forma cómo desde las instituciones políticas y sociales se busca influir en las posturas que asumen y en las diferentes maneras de representación de la violencia política (sus procesos y actores) en medio de los conflictos (Aróstegui, 1996, p. 20).

Es en este nodo entre actor político, instituciones políticas y sociales, conflictos permanentes por el poder y formas de representación, en donde adquiere connotación la opinión pública como una categoría histórica que problematiza la dimensión social en la que intervienen problemas y factores como los medios de comunicación y la disputa por imponer temas en la agenda pública; la socialización política y las tensiones con la oposición política; el interés por construir visiones hegemónicas frente a los acontecimientos pasados y políticos; el papel de los actores y organizaciones sociales frente a las incidencias informativas; y los ámbitos dinamizados por la sociedad en red donde la opinión pública encuentra otras manifestaciones y estímulos (Correa, 2018; Gamiño, 2011; Guillo, 2017; Llera, 1992; Márquez, 2007; Sampedro y Resina, 2010).

Con Habermas (1985) se ha comprendido que la construcción histórica y progresiva de una racionalidad crítica frente al diario acontecer de la vida que se manifiesta en el ámbito público fue determinante para configurar lo que se conoce como esfera pública. Un espacio en el que los actores políticos conviven con suficientes puntos de información, la que pueden contrastar, y que proviene de los diferentes ámbitos de la opinión, formales (Medios de comunicación, instituciones políticas, sociales y culturales) e informales (espacios de socialización) (Habermas, 1985). La opinión pública está caracterizada porque nada es inmune a la crítica de un público escritor experto en dirimir a través de la escritura cualquier tema de la agenda de debate de una comunidad (Zermeño, 2007). Los temas que interesan a la ciudadanía son revisados por numerosas voces (públicoescritor) que polemizan sobre aquello que es de interés de la sociedad y que en muchos sentidos ejercen una sostenida autorrepresentación como los voceros legítimos de la ciudadanía (Acevedo y Correa, 2016) y se asumen como los mediadores entre la complejidad informativa y el públicolector.

Ahora bien, si Habermas (1985) permite pensar la opinión pública en un sentido normativo en el que la esfera pública es racional porque cuenta con atributos modernos, capacidad de discusión, fuentes de información confiables y equilibrio de posturas, lo cierto es que Elizabeth NoelleNeumann (1995) también muestra que la opinión pública en contextos modernos y masificados puede resultar en un tema de mayorías que se imponen silenciosamente a las minorías. La opinión pública se somete a un juego de tendencias en donde aquellas ideas que en apariencia tienen mayor acogida sobresalen por sobre otras al punto de convertirse en opiniones generales. Dicho con otras palabras, para Noelle-Neumann (1995) la opinión pública funciona como una espiral del silencio porque existe una proclividad del público (del colectivo) a sumarse a la opinión mayoritaria frente a temas y problemas. Los costos de optar por la tendencia mayoritaria terminan siendo mucho menores y por eso el actor político desecha los puntos de vista difíciles de defender. Por supuesto, las tendencias mayoritarias en contextos politizados son influenciadas y direccionadas por las instituciones, las organizaciones, los gobiernos, y muy especialmente, por los medios de comunicación.

En qué medida se conectan los problemas de la Violencia Política y la Opinión Pública y a su vez cómo estos problemas son articulados a la perspectiva de la Historia del Tiempo Presente. Se deben advertir al menos dos puntos. El primero, la violencia política enfoca los conflictos por el poder entre los actores políticos y sociales y a las organizaciones que se lo disputan, bajo el entendido que cada uno se asume como legítimos (político, económico e institucional). Y el segundo, la opinión pública es el espacio abstracto donde se dinamizan las tendencias de pensamiento y representación acerca de aquellos actores y organizaciones que están inmersos en dichas tensiones por ostentar el poder.

Como un tercer punto adicional que se podría ubicar en el centro de la discusión, se encuentran las diversas formas cómo estos problemas entre el ejercicio de la violencia y la representación (positiva, negativa, matizada y estratégica) de la misma, trascienden en el tiempo para lograr que 
los procesos del pasado se mantengan vigentes. Significa que dichas cuestiones sostienen inquietudes por el comportamiento de los actores en aquellos acontecimientos que pasaron hace varias décadas.

En la relación entre violencia política, opinión pública y la perspectiva de Historia del Tiempo Presente, no sólo se encuentra el problema de cómo se explican los conflictos del pasado, también de cómo se mantienen y gestionan en el presente: cómo se usan de manera política las construcciones e interpretaciones más dominantes acerca de los pasados y cómo los actores y organizaciones combaten por validar e imponer ante la ciudadanía sus interpretaciones históricas particulares.

Para plantearse estas preguntas y proponer respuestas, es viable tomar en consideración la importancia que tiene la prensa en el estudio de estos fenómenos de opinión pública y violencia política para abordar problemas de Historia del Tiempo Presente. Toda vez que en las épocas pasadas con la importancia que tenían los medios impresos, la prensa política puede ser entendida como figura de mediación entre procesos sociales e históricos y actores políticos e instituciones.

\section{Análisis de la violencia política desde la prensa}

A nivel historiográfico es mayor el interés y la aceptación de la prensa como fuente de investigación en las últimas décadas. Atrás quedaron las épocas en que la prensa era vista con desprecio y condenada como fuente primaria por ser subjetiva y estar al servicio de quién la produce, como si las demás fuentes documentales, por ejemplo, las notariales o judiciales fueran objetivas, y realizadas por ángeles y no por actores políticos y sociales con intereses por nombrar y registrar de manera particular los acontecimientos. La historiografía hispanoamericana, de manera particular, ha dado grandes pasos en considerar la prensa en cuatro dimensiones: fuente primaria, objeto de investigación, empresa periodística y actor político (Acevedo y Villabona, 2020; Borrat, 1989; Del Palacio, 2006; Guerra, 2002; Hernández, 2017; Kircher, 2005).

Incluso, frente al carácter subjetivo que pudiera ser una de las críticas directas a la prensa, cabe señalar que esto la enriquece mucho más porque le permite dar cuenta de una amalgama de experiencias, opiniones y posicionamientos informativos de los actores sociales en el pasado, tal como lo señalan Acevedo y Villabona:

Las voces, las opiniones, los rumores, el debate, el clima político y cultural, los miedos, los enfrentamientos, los ataques personales, lo local, lo "subjetivo", todo esto está contenido en la prensa y, por tanto, enriquecen las miradas, especialmente en la historia política y cultural que trata de no quedarse solamente en lo institucional (2020, p. 350).

Se entiende que la prensa es una fuente útil para el análisis de la violencia política y la opinión pública. Con la prensa cobran sentido preguntas acerca de los aspectos relacionados con el campo de lo histórico-representativo. Es decir, la manera cómo un público-escritor presenta los hechos, a través de las páginas periodísticas, al público-lector para que éste construya una o varias posturas frente a los procesos de la agenda pública.

Aquí se propone entender que las características del público-escritor están dadas por la combinación de los intereses individuales y los colectivos-empresariales. En el primer ámbito se encuentran aspectos intangibles como la formación intelectual de los autores que escriben las noticias, elaboran las columnas y presentan reportajes, su posicionamiento ideológico frente al modelo económico y el régimen político. Y en el segundo ámbito se encuentran los lineamientos corporativos que pueden establecer los dueños de los diarios, limitando el margen de acción de los periodistas, bien sea de manera directa con la censura o de manera indirecta mediante la presión laboral de lo que está bien o mal publicar en un contexto de autocensura.

Así que los elementos que comunican los dos ámbitos podrían ser las marcas características del público-escritor frente a determinado tema, por ejemplo, el feminismo, el capitalismo versus comunismo, la violencia política y la acción colectiva, etc. Identificar estas condiciones de 
producción discursiva, son en última instancia, las que permiten entender el porqué de una u otra manera de publicar una noticia y presentar a un actor político, como un héroe o como un villano. Por añadidura, el estudio de la prensa conlleva otros problemas además de los comunicativos de la opinión pública, como los del análisis de contenido, las representaciones colectivas y la propaganda y socialización política. Definirse por alguno de estos posicionamientos implica revisar las fuentes, que son los diarios mismos, y reelaborar los problemas de investigación posteriormente con ayuda de la teoría. Se trata de abordar el recorrido desde los datos (las fuentes de prensa) hacía la teoría, no de manera inversa como. Se asume que la prensa, al igual que los demás medios de información, tiene una naturaleza discursiva a través de la que se accede a la opinión pública y, a la vez, se participa de sus debates (Aruguet, 2001).

\section{El Sol de Sinaloa, uno de los Soles de José García Valseca}

El Sol de Sinaloa comenzó a circular en Culiacán el 1 de diciembre de 1956, como uno más de los 37 diarios que tuvo en circulación la Cadena García Valseca en los años sesenta y setenta. Esta organización que fue creada desde finales de los años treinta por José García Valseca, exgeneral de la Revolución Mexicana, se caracterizó por mantener una línea editorial oficialista en defensa de los gobiernos del Partido Revolucionario Institucional (PRI), la cual acompañó de un posicionamiento férreamente anticomunista, siendo éste el prisma para observar el acontecer noticioso mexicano. A comienzos de los años setenta la Cadena García Valseca se convirtió en la Organización Editorial Mexicana (OEM) y pasó a manos de Mario Vázquez Raña. Sin embargo, el cambio de dueño y nombre no implicó una transformación de la visión editorial, más bien el fortalecimiento de la misma.

La postura oficial de la Cadena García V alseca y, por lo tanto, de El Sol de Sinaloa fue la lucha contra la propagación del fantasma comunista, alertar sobre la peligrosidad del expansionismo de la Unión Soviética, la Revolución Cubana y los diferentes grupos guerrilleros que fueron surgiendo por el continente latinoamericano. Sobre José García Valseca, originario de Puebla, se sabe que fue una persona interesada en la apertura de diarios locales que poco a poco fue articulando en una organización más grande. Enrique Cordero y Torres, señaló que era un joven que prefería el trabajo que el juego, con un marcado gusto por los periódicos y las revistas (Monsiváis, 2003, p. 84).

El primero de los periódicos que editó fue El Fronterizo de Juárez en 1943. El crecimiento de su monopolio periodístico no fue obra de la casualidad. Su formación militar adquirida en la revolución mexicana, lo llevó a cultivar relaciones y amistades políticas como las del gobernador poblano Maximino Ávila Camacho que supo aprovechar en beneficio de sus empresas. La construcción de su emporio puede dividirse en tres momentos. El primero, se caracterizó abrir nuevos periódicos utilizando viejos equipos, en el segundo, encontró la expansión del negocio y la modernización de equipos e instalaciones. Y, en el tercero, introdujo nuevas tecnologías como el Off Set, las imágenes a color y el posicionamiento de tres diarios en las principales tres ciudades del país, Ciudad de México, Guadalajara y Monterrey (Rincón, 2012, p. 63).

\section{Figura. 1. José García Valseca en las páginas de E1 Sol de Sinaloa}

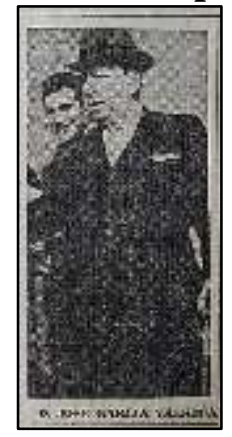

Fuente: El Sol de Sinaloa (1973, marzo, 18, p. 1) 
Las páginas de los soles fueron el espacio para reproducir los principios gubernamentales del estado posrevolucionario mexicano (Gil, 2020). Las celebraciones del día de la "Libertad de Prensa" o los aniversarios de la cadena fueron momentos propicios para reafirmar su compromiso con las causas gubernamentales:

el objetivo, el motor que ha movido el espíritu de creación del señor García Valseca, es el servicio a nuestra patria, que está por encima de cualesquiera otros intereses. Y servir a la Patria es servir, en consecuencia, a los miembros de la comunidad mexicana. Esta ha sido la regla diamantina que, sin la menor desviación, ha seguido y sigue Don José García Valseca (El Sol de Sinaloa, 1970, enero, 8, p. 6).

Los diarios de la Cadena García Valseca tuvieron como principal objetivo evitar que el comunismo y las ideologías de izquierda llegaran a las ciudades o regiones mexicanas (Gil, 2020). La Unión Soviética, y en general, el llamado mundo socialista representó un peligro para la humanidad. Como se ha señalado, las características de los soles fueron visibles en la mayoría de los 37 diarios que hubo en circulación nacional.

El Sol de Sinaloa que pudo circular debido a algunos créditos y la compra de máquinas de impresión en Guadalajara se ubicó en la avenida Ángel Flores, entre las calles Domingo Rubí y Morelos en el pleno corazón de Culiacán (Ontiveros, 2017, p. 202). Su inauguración estuvo presidida por el gobernador, Rigoberto Aguilar Picos, el Presidente Municipal, Luis Flores Sarmiento, y el director del nuevo impreso, Ernesto Zenteno Carreón (Ontiveros, 2017). Durante el gobierno de Leopoldo Sánchez Celis la rotativa se trasladó al Boulevard Leyva Solano con esquina Avenida Aquiles Serdán. El Sol de Sinaloa se convirtió en un referente para los lectores de Culiacán, Sinaloa.

\section{Violencia política y tinta periodística}

Los diarios de la Cadena García V alseca argumentaron que el comunismo y las guerrillas no se podían permitir en México. Esta idea la convirtieron en su principal premisa para dar cobertura a los procesos de la violencia política de los años sesenta y setenta. Un posicionamiento que estaba en función del fortalecimiento del Estado nacional y sus instituciones, producto de la Constitución y la ideología emanada de la Revolución Mexicana. Esta condición permitió que a lo largo de una década sus páginas polemizaran en contra del fantasma que representaba la izquierda, como un problema más allá de las fronteras nacionales. Desde las páginas de sus diarios, como El Sol de Sinaloa, se desplegó una pedagogía política que socializó una ideología gobiernista en contra de todos aquellos símbolos y personalidades de izquierda del orden nacional e internacional, al considerar que se trataba de expresiones políticas ajenas a la realidad nacional. Se puede apreciar un esfuerzo periodístico por construir la idea, a través de su tinta diaria, de que México se encontraba a salvo de cualquier intervencionismo ideológico:

Los que quieren otro cambio, es obvio que no desean un retorno a los tiempos de Don Porfirio Díaz. Dicen que se haga mayor justicia al pueblo. Los que esconden es que quisieran sustituir nuestras instituciones por otras dictatoriales y análogas a las que rigen en países que adoptaron el llamado régimen marxista-leninista. Es una trampa y un engaño lo del famoso cambio de estructura (El Sol de Sinaloa, 1970, febrero, 14, p. 6).

Se puede ver que los regímenes políticos distintos al mexicano eran promocionados como cercanos a las ideologías dictatoriales y por lo tanto carentes de posibilidad alguna en la esfera pública mexicana. Se les consideraba como modelos políticos y de sociedad fallidos, condenados a la pobreza y el autoritarismo. Sin embargo, esta narrativa generaba una paradoja. Por un lado, el público-escritor se mostraba convencido de que las ideologías de izquierda no tenían cabida en el país, entre otras razones, porque México ya había realizado una revolución social a comienzos del siglo XX. Y por el otro lado, el mismo público-escritor buscaba convencer al público-lector de que existía dicha amenaza como una posibilidad latente. Como si fuera una verdad relativa que debía ser creída por la ciudadanía. 
Las páginas periodísticas reivindicaban las acciones militares, la persecución y el asesinato de mexicanos bajo el argumento de salvaguardar la seguridad nacional. La estrategia más soterrada era la caricaturización del enemigo político, al otro se le convertía en un enfermo, comunista, negativo, rebelde, guerrillero, es decir, en un sujeto que en apariencia no tenía los mismos derechos o que no merecía gozar de la misma legitimidad del resto de los ciudadanos que sí apoyaban al gobierno del PRI. De manera reiterada, sus editoriales consagraban a los gobernantes priistas como un presente superior y muy distante del pasado decimonónico que la Revolución Mexicana había superado:

En el segundo capítulo de la obra del Presidente Díaz Ordaz, o sea en el orden político, en el mismo discurso que comentamos se subraya como se han mantenido intactas nuestras instituciones constitucionales de la libertad. Evitamos la anarquía, pero conservamos el orden sin suspender las garantías constitucionales y de los distintos grupos de la comunidad mexicana. Sin juzgar de los problemas de otros países, hemos de escribir que varias naciones de nuestra América han tenido que restringir libertades y la vigencia circunstancial de sus constituciones, para hacerle frente a peligrosas embestidas de los agitadores de doctrinas disolventes. México continúa su evolución económica, social y política sin perturbaciones, en paz y dentro del orden, para proyectarse hacia el futuro en forma promisoria (El Sol de Sinaloa, 1970, junio, 24, p. $5-6)$.

Estas tesis argumentadas y aceptadas como indestructibles hicieron que la prensa asumiera como poco probable la emergencia de organizaciones armadas de izquierda en el país, debido a la aparente "inmunidad" de la que gozaba, otorgada por las ventajas sociales latentes después de la Revolución Mexicana. En efecto, la revolución continuó siendo el "paraguas" defensivo, como repetidamente lo afirmaban funcionarios públicos o candidatos presidenciales identificados con el PRI, contra todo aquello que implicara disidencia o participación política no alineada.

En el discurso del priismo tanto la Revolución Mexicana como el modelo de desarrollo corporativista del periodo posrevolucionario, había logrado escindir las diferencias sociales y las marcadas desigualdades e inequidades entre sectores populares, medios y altos, dando a los primeros dos las oportunidades de educación y empleo necesarias para la movilidad social. El presidente de la República, en este caso Luis Echeverría Álvarez, como principal vocero legitimador de esta posición la declaraba en diferentes espacios, nacionales e internacionales, posiblemente convencido de la resonancia que tendría en el país su visión. Un ejemplo muy representativo fueron las declaraciones al diario San Diego Unión en Estados Unidos:

En una entrevista concedida al director del diario californiano, "San Diego Union", el Licenciado Luis Echeverría Álvarez expresó su convicción de que el comunismo no es problema ni amenaza para México, en virtud de que nuestro movimiento revolucionario había logrado la unificación de la clase media, campesina y trabajadora, en torno al bien común del país (El Sol de Sinaloa, 1970, marzo, 24, p. 6).

No obstante al esfuerzo entre gobierno mexicano y prensa por posicionar en la opinión pública la premisa de la improcedencia de las tesis subversivas en el país, lo cierto es que poco a poco fueron tomando fuerza los argumentos que señalaban un mundo convulsionado por diversos conflictos internacionales y el descontento generado entre segmentos de las clases medias mexicanas que todavía no lograban insertarse de manera adecuada en los beneficios de la modernidad y del llamado Milagro Mexicano de años atrás. Este malestar venia de las personas cercanas a la vida universitaria que tenían presente la represión estatal del 2 de octubre de 1968 hacía los estudiantes en Tlatelolco. Así que las guerrillas, aunque se hubiesen escondido por algún tiempo o difuminado en la tinta periodística, no dejaban de ser un problema latente:

Muchos piensan cuando se advierten fenómenos de subversión o se ejecutan actos de sabotaje y terrorismo, que todo eso se debe a individuos aislados o a pequeños grupos inconformes con la sociedad en que viven. No se advierte -o no se quiere advertir- que, 
desde las inquietudes juveniles, la afición a las drogas y las brechas generacionales, hasta la guerrilla urbana y la revuelta armada contra el gobierno constitucional, forman parte de una sola conspiración que abarca a todos los países libres del mundo (El Sol de Sinaloa, 1970, febrero, 16, p. 6).

Se trataba pues de una amenaza persistente contra la seguridad nacional, no exclusiva de las guerrillas, porque también incluía a los jóvenes universitarios, a los consumidores de drogas a los inconformes sociales en general. Así mismo, la conjura no sólo estaba escenificada contra México, sino contra "todos los países libres del mundo" como se aprecia en la nota anterior.

Esta narrativa periodística no es más que el reflejo de la inscripción de México en las discusiones de la Guerra Fría Latinoamericana, en la cual, como sostiene Pettinà (2018), hubo un interés de parte las élites nacionales por aprovechar este marco ideológico y la pugna bipolar entre EEUU y la Unión Soviética para retraer algunos avances en las condiciones sociales que se habían logrado en la primera mitad del siglo XX.

En 1971 la prensa denunció que en México las autoridades habían descubierto un complot guerrillero encabezado por el Movimiento de Acción Revolucionaria (MAR). Dicho "complot internacional" venía fraguado desde la Unión Soviética con el apoyo del gobierno de Corea del Norte, en apariencia se trataba de dar formación militar y apoyo económico a grupos de ciudadanos mexicanos. El hecho fue revelado en las noticias nacionales como si se tratara de un gran descubrimiento, olvidando que en el contexto de la época la colaboración y circulación transnacional de militantes era un fenómeno recurrente:

Como hemos asentado ya, es muy reveladora la información sobre este complot contra México. Desde Moscú, los "becarios" arreglaron con la embajada de Corea del Norte, allí que otro grupo de mexicanos se fuese a Pyong Yang para recibir adiestramiento político-militar. Los promotores recibieron diez mil dólares para el traslado a Corea del Norte del grupo de mexicanos que pasó por Berlín Oriental y de allí a través de la enorme URSS hasta la capital coreana norteña, pese al visible tipo de no coreanos y al idioma español. Todo con anuencia de las autoridades soviéticas, lo que comprueba que el gobierno norteño de Corea está dentro de la zona de influencia de Moscú y no de Pekín (El Sol de Sinaloa, 1971, marzo, 17, p. 6).

Como se puede ver, de manera general, lo que se estableció en los años setenta fue una manera de cubrir los problemas mexicanos desde una óptica que culpó a los guerrilleros -y a la oposición política- de todo lo negativo que ocurría. Los principales tópicos de la discusión fueron el fantasma del comunismo internacional, los problemas de la guerra fría, la intervención soviética a través de agentes secretos o mediante intercambios académicos de supuestos estudiantes, y más especialmente, la aparición de las guerrillas como aquel gran fantasma que tanto atemorizaba a los gobiernos del PRI.

Una pregunta clave es ¿por qué se presentó este tipo de comportamiento informativo? En parte, porque la aparición de estas organizaciones guerrilleras como nuevos actores supuso hacer visibles diferentes problemáticas que existían en el país de tiempo atrás, pero que la ilusión del progreso posrevolucionario habían logrado ocultar durante décadas, generando un estado de cosas en el que la voluntad "misericordiosa", "tricolor" y "guadalupana" del Estado mexicano, en cabeza de su presidente de la República, tenían en sus manos la voluntad sobre todo aquello que acontecía y también sobre lo que no pasaba. Las guerrillas, y en general las características de la violencia política, fueron el resultado de algo no contemplado con suficiente claridad: El gobierno, y por el mismo conducto los medios de comunicación, se desgastaron en la crítica constante a un fantasma internacional que no podría reproducirse en México, cuando en sus márgenes y zonas sombrías ya se germinaba el descontento y la demanda por un aumento en la participación política efectiva, por una sociedad más democrática y equitativa, por una repartición menos austera y corporativista de las ventajas del progreso económico de los años precedentes. 
En el siguiente cuadro, a modo de resumen cuantitativo, se ofrecen algunos elementos de lo que fue la cobertura en los cinco años más críticos de la década, aquellos que coincidieron con la emergencia del fenómeno guerrillero y con mayor énfasis periodístico en la supuesta defensa de la soberanía frente al enemigo exterior.

De esta información se puede inferir que el público escritor fue contundente en afirmar los peligros de las ideologías que circulaban por el país, así como las implicaciones de los actores políticos que resistían al régimen, de ahí que entre 1970 y 1974 los artículos con autor visible fueran siempre la mayoría en la cobertura informativa, se trataba pues de un público-escritor consciente de lo que decía y convencido de que gozaba de la legitimidad para opinar frente a las cuestiones, que en apariencia, más aquejaban a la sociedad mexicana.

Tabla 1. Tipos de discursos en E1 Sol de Sinaloa.

\begin{tabular}{|c|c|c|c|c|c|c|c|c|c|c|}
\hline Tipo & \multicolumn{2}{|c|}{1970} & \multicolumn{2}{|c|}{1971} & \multicolumn{2}{|c|}{1972} & \multicolumn{2}{|c|}{1973} & \multicolumn{2}{|c|}{1974} \\
\hline $\begin{array}{c}\text { Artículos con } \\
\text { autor }\end{array}$ & 31 & $38.75 \%$ & 31 & $32.97 \%$ & 35 & $24.82 \%$ & 40 & $45.97 \%$ & 46 & $40.70 \%$ \\
\hline $\begin{array}{c}\text { Artículos sin } \\
\text { autor }\end{array}$ & 18 & $22.50 \%$ & 42 & $44.68 \%$ & 74 & $52.48 \%$ & 40 & $45.97 \%$ & 64 & $56.63 \%$ \\
\hline Editoriales & 21 & $26.25 \%$ & 14 & $14.89 \%$ & 12 & $8.51 \%$ & 4 & $4.59 \%$ & 3 & $2.65 \%$ \\
\hline Desplegados & 0 & $0 \%$ & 2 & $2.12 \%$ & 15 & $10.63 \%$ & 3 & $3.44 \%$ & & \\
\hline Epígrafes & 10 & $12.50 \%$ & 1 & $1.06 \%$ & 4 & $2.83 \%$ & & & & \\
\hline Telegramas & & & 4 & $4.25 \%$ & 1 & $0.70 \%$ & & & & \\
\hline Totales & 80 & $100 \%$ & 94 & $100 \%$ & 141 & $100 \%$ & 87 & $100 \%$ & 113 & $100 \%$ \\
\hline
\end{tabular}

Fuente: Elaboración propia.

De igual importancia fueron las editoriales que permitieron al diario, El Sol de Sinaloa, sentar una posición clara respecto de los acontecimientos que se presentaban. No una autoafirmación empresarial de que el sentido corporativo estaba acorde a las necesidades del país y no tanto una visión desde sus periodistas.

Los artículos de opinión y las noticias, al igual que las editoriales, fueron los discursos que fundamentaron el interés de la prensa por orientar la opinión pública hacia el temor a la izquierda, la oposición y el comunismo. Las imágenes periodísticas y las caricaturas políticas se sumaron a este aparato discursivo, en forma de representaciones que apelaron a la exageración y deformación de los gestos, para generar símbolos cargados de significado para la opinión pública de la época. En el caso de las imágenes periodísticas, claramente más poderosas en su capacidad de orientación que los discursos textuales, El Sol de Sinaloa apeló por un juego de espejos negativo, utilizando sus primeras páginas para presentar aquel oscuro camino escogido por los países que se acercaban al socialismo (entendido burdamente en la traducción conceptual de la prensa de la época como toda la izquierda) para mostrar al público-lector mexicano los problemas económicos, sociales y de violencia que todo ello generaba.

Por lo anterior, el manejo de las imágenes periodísticas hizo eco de las herramientas de la propaganda y socialización ideológica. Cuando se trataba de generar representaciones sobre el enemigo (el otro) fueron fundamentales las apuestas de los más minuciosos aspectos, como puede ser los titulares, el tamaño de los mismos, el color con el que son impresos, etc. La imagen periodística 2, por ejemplo, da cuenta del uso del color rojo para comunicar los aspectos referidos a las movilizaciones de los estudiantes en una clara asociación entre el color de la sangre y las acciones implementadas por los jóvenes para agenciar sus demandas. 
Figura. 2. Los colores en el manejo de la información.

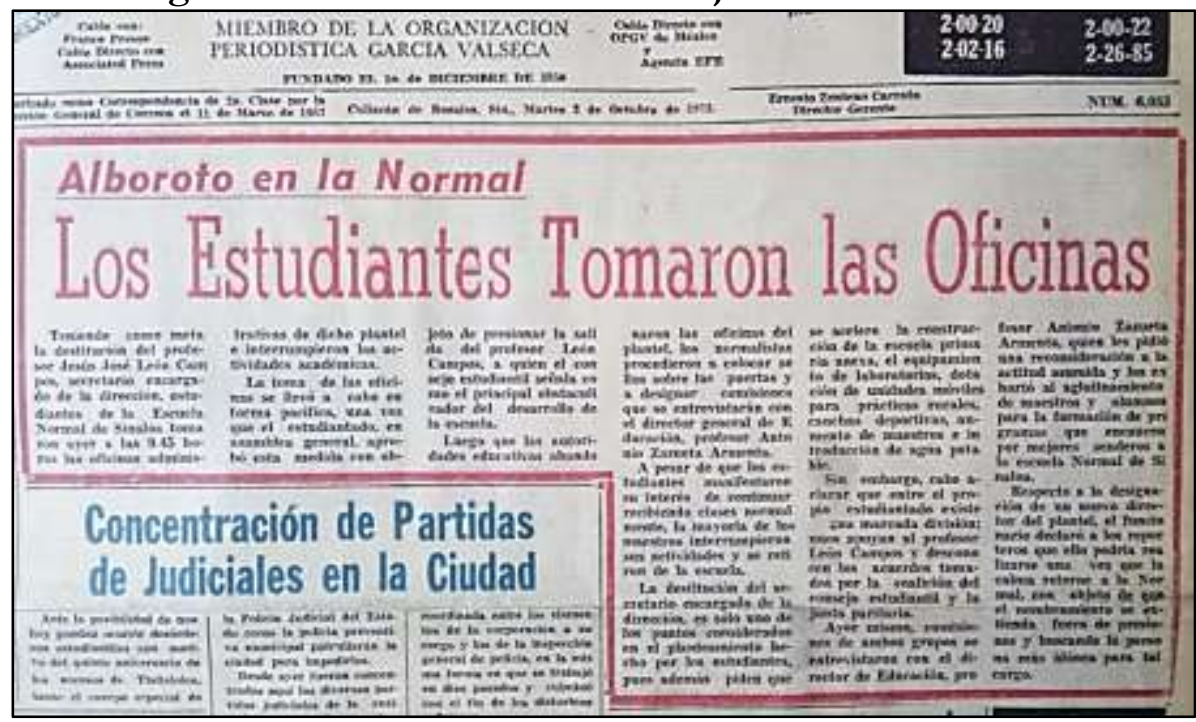

Fuente: El Sol de Sinaloa (1973, octubre, 2, p. 1).

El manejo de la nota este revestido de una contradicción. El titular "Alboroto en la Normal. Los Estudiantes Tomaron las Oficinas" -en color rojo- advierte de una situación tensa protagonizada por los estudiantes en esta escuela de Sinaloa. Así se le comunica al público-lector la siguiente premisa: "una vez más los estudiantes están haciendo desmanes", argumento que fue recurrente durante y después de octubre de 1968 en la prensa mexicana. Sin embargo, -y ahí se encuentra la contradicción que señalamos- en la nota se puede leer que los estudiantes después de una asamblea decidieron manifestarse por las acciones del profesor Jesús José León Campos (exigiendo su renuncia) y tomaron "de manera pacífica" las oficinas de la administración, además se agrega que los estudiantes insistieron en continuar con las clases, pero que fueron los maestros quienes decidieron suspenderlas.

Cabe preguntarse ¿qué sentido tiene darle cobertura a una noticia local a pesar de que se trató de un acontecimiento de rutina en una escuela y, sobretodo, usando el color rojo?, se trató pues de mantener la línea argumentativa mediante una fórmula de representación que equipara los estudiantes como las más dóciles víctimas del fantasma del comunismo. El mismo que, según la prensa, convertía a los jóvenes en desordenados e insatisfechos, aunque nada tuviera que ver lo uno con lo otro. El Sol de Sinaloa simplemente dio continuidad a sus formas argumentativas instrumentadas desde los acontecimientos de 1968.

Desde el concepto de fórmula de representación que proponen Uribe y Ureña se puede entender que el uso del color rojo en la prensa mexicana -podría decirse mundial- en los años sesenta remitía a un sentido sobre el otro, es decir, lo diferente, que en el contexto de la Guerra Fría se explicaba como comunismo, máxime al ubicarlo al lado de "estudiantes" y "alboroto". Pero no sólo en los colores se pudo ver está reiteración en delimitar los problemas para la opinión pública. En las noticias que cubrían los problemas de la violencia política latinoamericana ocurrió igual. Los acontecimientos eran diagnosticados como el peor escenario con el interés de visibilizar la necesidad de evitar que actores, organizaciones y procesos similares se dieran en México.

Lo anterior, se puede corroborar al revisar la imagen periodística 3 en la que se está informando de la infiltración comunista en México dirigida desde Cuba por Fidel Castro. El sustrato de la noticia advierte de la reunión de líderes guerrilleros en Guadalajara para conspirar contra el país con el

\footnotetext{
${ }^{4}$ Conviene señalar lo dicho por María Victoria Uribe y Juan Felipe Ureña frente a las fórmulas de representación, un concepto que “(...) puede ayudar a concretar las estrategias de representación que unos y otros tienen para crearse imágenes de los "otros" y de "sí mismos". Una fórmula de representación se refiere a un conjunto de dispositivos culturales que han sido conformados históricamente y, al mismo tiempo, gozan de cierta estabilidad, de modo que son fácilmente reconocibles por el lector o el espectador (...)" (Uribe y Ureña, 2019, p. 27).
} 
liderazgo de Lucio Cabañas, que lograría unificar todas las organizaciones guerrilleras. Sea como fuere, la noticia misma se encarga de confirmar que no hay fuente para lo que señala. Esto es, que se trata de una información no confirmada, un rumor informativo, o como dicen en algunos lugares de México, un "mitote" noticioso para remarcar el carácter poco fiable de lo publicado. A pesar de ello, El Sol de Sinaloa decidió publicar el titular "Denuncian que Fidel Castro Apadrina Guerrilla", en un tamaño de fuente mucho mayor, antecedido por "Hubo Junta Roja en Guadalajara".

Figura. 3. Llamados, alertadas y denuncias frente al problema al que se enfrentaba México.

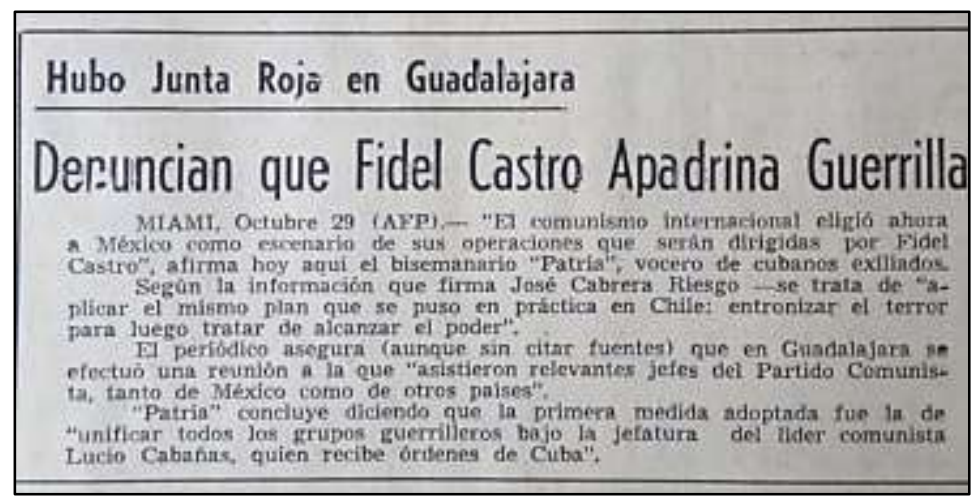

Fuente: El Sol de Sinaloa (1973, octubre, 29, p. 3)

En la misma lógica de la imagen periodística 3 se encuentra la 4. En septiembre de 1973 con motivo de la caída del gobierno chileno de Salvador Allende, la prensa mexicana en general, la cadena García Valseca en particular, y El Sol de Sinaloa en específico, aprovecharon para atemorizar la opinión pública a través de las primeras planas con imágenes que (modo espejo y modo metáfora) reflejaban el caos y la tragedia de los países vecinos que transitaban por el peligroso camino de la izquierda (Gil, 2020).

Esta página referente a lo sucedido en Chile en la mañana del 11 de septiembre de 1973, en una primera apariencia no tendría mucho que ver con lo acontecido en México durante la década por ser un problema latinoamericano frente a uno nacional. No obstante, cobra sentido en la argumentación de este artículo, cuando se considera que durante los últimos meses (anteriores de septiembre de 1973), El Sol de Sinaloa fue cubriendo todos los acontecimientos de Chile, los mismos que daban cuenta de una crisis política cada vez más profunda, que se radicalizaba en tanto que la intervención de Estados Unidos aumentaba. Sin embargo, para el diarismo mexicano se trataba de las consecuencias "entendibles" que tenía que afrontar un pueblo por escoger el camino fácil, la vía del fantasma, el socialismo de Salvador Allende. Por eso una vez que fue derrocado el presidente Allende, se utilizaron las primeras páginas para, ahora sí con mayor contundencia, advertir de la peligrosidad que se asomaba para México, con el título "Cuartelazo en Chile; el Presidente, Derrotado, se Mató", acompañado por un solidario "Pesar del gobierno mexicano". 
Figura. 4. Caída de Salvador Allende en Chile.

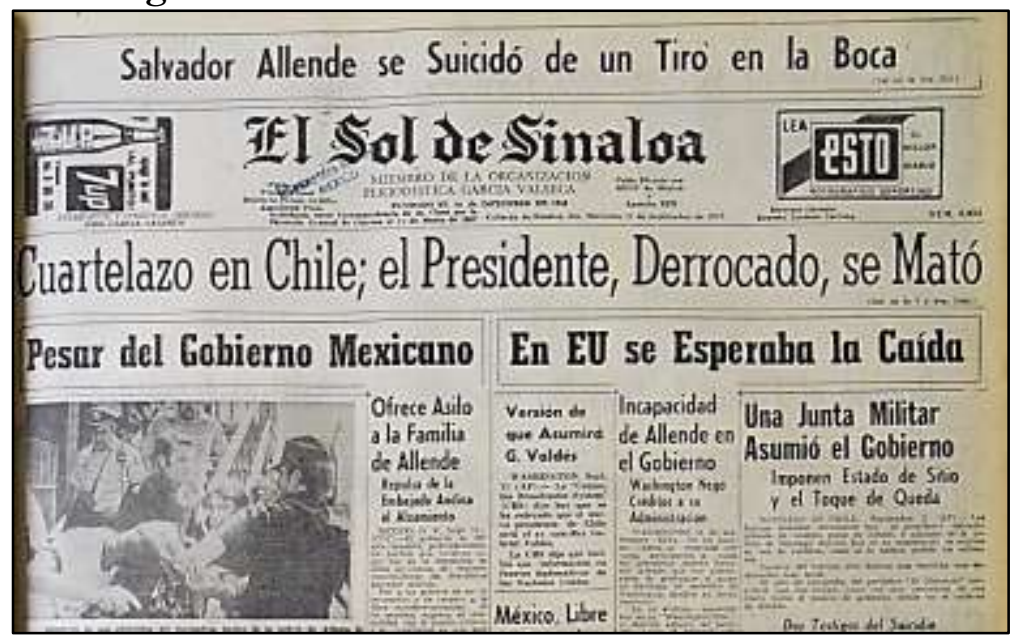

Fuente: El Sol de Sinaloa (1973, septiembre, 12, p. 1).

El Sol de Sinaloa (ni sus editorialistas ni columnistas) aprovecharon lo ocurrido en Chile para hacer un llamado a la regulación de la intervención extranjera de Estados Unidos, por el contrario, utilizaron este acontecimiento como una razón para ahondar en la persecución comunista y en la socialización del modelo mexicano hibridado con el capitalismo estadounidense como la única opción legítima de desarrollo.

\section{Conclusiones}

La presente es una mirada sucinta de los principales tópicos que marcaron la cobertura informativa por parte de los diarios de la Cadena García Valseca, en particular de El Sol de Sinaloa, al problema de la violencia política en los primeros años de la década de 1970. Este panorama permite visualizar algunos ejes que se mantienen a través del tiempo, sobre todo aquellos que están relacionados con el comportamiento de los medios de comunicación y los gobiernos frente a la tensión entre insurgencia y contrainsurgencia, entre ejercicio del poder y oposición política, y entre demandas sociales y respuesta a ellas.

La prensa, como el caso de El Sol de Sinaloa, contribuyó a denigrar y sobredimensionar la presencia de los grupos armados como los responsables de poner en riesgo la seguridad nacional. En el pasado de violencia política que se manifestó en diversas regiones del país, el gobierno sólo encontró un enemigo externo: la izquierda comunista en todas sus variantes. Los discursos, declaraciones de prensa, reportajes, editoriales y las imágenes periodísticas, evidenciaron el tratamiento sesgado con el que se manipuló la realidad, donde un segmento de la sociedad mexicana apeló al uso de las armas para confrontar al Estado, lo que trajo como resultado una representación colectiva negativa de militantes y organizaciones políticas y militares. De forma que se trató de un ejercicio sistemático de influencia en la opinión pública del país.

Si se toma como punto de reflexión la relación entre el pasado y el presente, se puede encontrar que los gobiernos han sido actores que dinamizan la violencia política, en especial porque su respuesta a los conflictos por las demandas sociales, políticas y económicas, han sido las medidas autoritarias y las prácticas represivas.

Frente a la construcción de interpretaciones que expliquen los acontecimientos de conflicto, violencia política y protesta social, el gobierno mexicano ha contestado a lo largo de cuatro décadas con la imposición de memorias oficiales, en las que se deslegitiman los actores sociales y políticos inmersos en los procesos históricos. Un comportamiento que es recurrente no sólo en el caso de México sino de los países latinoamericanos como Argentina, Chile, Uruguay, y Colombia, entre otros. 
La construcción de estas memorias oficiales ha resultado muy importante para los gobiernos porque es una forma de justificar el comportamiento militar y represivo que las fuerzas militares, de policía y de inteligencia, han tenido en distintos hechos a través del tiempo. Es, además, una forma de validar las posiciones de otros actores como los empresarios o los medios de comunicación. Así mismo, es una estrategia política que permite realizar un uso político del pasado, influir en la opinión pública y establecer una visión no sólo oficial sino hegemónico del pasadopresente, porque impide que entre la ciudadanía surjan cuestionamientos a la versión contada, divulgada y aceptada.

Este ámbito de la violencia política en perspectiva de Opinión Pública e Historia del Tiempo Presente, aunque cada día tiene más estudios, todavía requiere más miradas investigativas. En términos de una agenda de investigación cabe señalar la pertinencia de profundizar en el análisis de las periodizaciones. Si bien es cierto que la primera mitad de la década del 70 se caracterizó por un aumento de la violencia política, también lo es que se trató de un fenómeno que por lo menos merece reflexiones e indagaciones desde una mediana duración. Es pertinente pensar las relaciones que existen entre las coyunturas que marcan la violencia política en México con periodos de violencia anteriores (como la Revolución Mexicana) y posteriores (como la lucha contra las organizaciones criminales asociadas al narcotráfico). Así mismo, parece haber un consenso investigativo en la necesidad de preguntarse por la conveniencia de seguir utilizando expresiones como Guerra Sucia para denominar este periodo de estudio, toda vez que como sostiene Ovalle (2020) esto permite que el Estado mismo (principal actor represivo) se justifique al utilizar los dispositivos de represión como la única posibilidad en el marco, precisamente, de una guerra sucia. Insistir en esta denominación puede servir para que las organizaciones de inteligencia arguyan que en la defensa patriótica tuvieron que recurrir a prácticas no contempladas. Es decir, una guerra sin el cumplimiento de normas mínimas como la defensa y garantía de los derechos humanos. Aunque claro, como el mismo Camilo Ovalle (2020) lo reconoce, se trata de una denominación muy utilizada por las primeras organizaciones que comenzaron a hacer visible los problemas y las consecuencias de la violencia política en México, y en ese sentido, cobra relevancia. No obstante, la invitación a repensar y reconceptualizar las nociones básicas de estas investigaciones es necesaria. En cuanto al papel de los medios de comunicación, y en especial de la prensa, todavía debe ser profundizado con mayor rigor. Si bien, como pauta general, se encuentra la adscripción cómplice de los impresos hacía la lucha contrainsurgente adelantada por los gobiernos priistas. Cabe la pregunta por los matices en esta cobertura: ¿Cuáles son las diferencias regionales en la forma de prensar los hechos y en los intereses por hacerlo?, ¿Cuáles son las diferencias entre la prensa priista o panista en la cobertura de estos problemas?, ¿Cuáles son las implicaciones de la cobertura periodística de la Cadena García V alseca al ser una organización con el poder de circulación -gracias a sus 37 diarios- por todo el país?

Un aspecto relevante y necesario para poder enmarcar la cobertura hecha de estos fenómenos por parte de la prensa mexicana, es la urgencia de comparar el caso mexicano con otros casos latinoamericanos, no exclusivamente los del Cono Sur -donde los procesos represivos fueron fulgurantes- sino también con otros países como los andinos (Colombia y Perú) y los centroamericanos donde la pauta represiva ha sido variable en su intensidad, pero se podría decir que muy constante. El factor comparativo y transnacional puede aportar mucho a esta mirada, en la lógica que lo han propuesto Ernesto Bohoslavsky (2011) y Aldo Marchesi (2019) para el caso de los procesos de derechas y militantes de nueva izquierda en Suramérica, respectivamente.

Conviene dejar abierta una invitación a trazar líneas de continuidad donde se han dado por sentadas las rupturas: La sociedad actual rompió con el comportamiento represivo de las fuerzas militares en los años sesenta, setenta y ochenta del siglo pasado, o más bien son tendencias que se han mantenido, aunque los contextos políticos y sociales se modifiquen. En la misma línea, la forma cómo los medios de comunicación se posicionaron frente a los fenómenos guerrilleros durante la Guerra Fría Latinoamericana, son muy distantes a la manera cómo en la actualidad se 
asumen frente a problemas de protesta y movilización social en sociedades desiguales e inequitativas. La propensión a estigmatizar los actores y organizaciones sociales quedó en el pasado o sigue siendo la manera predilecta como los gobiernos -y los medios de comunicación en su auxilio- enfrentan los efectos de la perdida, cada vez mayor, de legitimidad.

Por último, en esa tesitura cómo aprovechar el conocimiento de la realidad social de hace tres y cuatros décadas para comprender la violencia política que registra en los países de América Latina en el último tiempo. Usufructuar el conocimiento del pasado para poder explicar mejor, por ejemplo, las acciones represivas y violatorias de derechos humanos en países del mismo continente como Chile (gobierno de Sebastián Piñera) y Colombia (gobierno de Iván Duque). Tal vez, en la mirada a la violencia política en México durante los años setenta se pueden encontrar pistas para pensar la violencia política reciente y de paso se profundiza en la opinión pública desde una mirada de la Historia y las Ciencias Sociales.

\section{Referencias bibliográficas}

Acevedo, Álvaro, y Correa, Jhon Jaime. (2016). Tinta roja. Prensa, política y educación en la Republica Liberal (1930-1946). El Diario de Pereira y Vanguardia Liberal de Bucaramanga. Primera edición. Universidad Industrial de Santander. Colombia.

Acevedo, Álvaro, y Villabona, Juliana. (2020). La prensa como fuente documental para el análisis y la investigación social. Historia y Memoria. No, 20. Colombia (pp. 347-373). DOI: https://doi.org/10.19053/20275137.n20.2020.8266

Allier, Eugenia. (2018). Balance de la historia del tiempo presente. Creación y consolidación de un campo historiográfico. Revista de Estudios Sociales. No. 65. Colombia (pp. 100-112). DOI: https://doi.org/10.7440/res65.2018.09

Aróstegui, Julio, Calleja, Eduardo, y Souto, Sandra. (2000). La violencia política en la España del siglo XX. Cuadernos de Historia Contemporánea. No. 22. España (pp. 53-94).

Aróstegui, Julio. (1996). La especificación de lo genérico: la violencia política en la perspectiva histórica. Hispania Nova. Revista de Historia Contemporánea. No. 132-133. España (pp. 9-39).

Aruguet, Natalia. (2001). Los medios y las fuentes de información. La construcción de la agenda de mediática durante la privatización de las telecomunicaciones en Argentina. En Chardón, María Cristina. Transformaciones del Espacio Público. Los autores, las prácticas, las representaciones. La Crujía Ediciones. Argentina.

Bohoslavsky, Ernesto. (2011). Historias conectadas y comparadas del Antipopulismo de derecha en Argentina, Brasil y Chile a mediados del siglo XX. Anuario IHES. No. 26. Argentina. (pp. 239-250).

Borrat, Héctor. (1989). El periódico, actor político. Primera edición. Gustavo Gili, S.A. España.

Braudel, Fernand. (1968). La Historia y las Ciencias Sociales. Primera Edición de Bolsillo. Alianza Editorial. España.

Castells, Manuel. (2009). Comunicación y poder. Primera edición. Alianza Editorial. España.

Correa, Jhon Jaime. (2018). Oposición política en la Nueva Granada: Un análisis de la confrontación entre los periódicos La Bandera Nacional y El Argos (1837-1839). Ciencia Nueva. Revista de Historia y Política. Volumen 2, No. 1. Colombia (pp. 02-21). DOI: https://doi.org/10.22517/25392662.18241

Del Palacio, Celia. (2006). La prensa como objeto de estudio. Panorama actual de las formas de hacer historia de la prensa en México. Comunicación y Sociedad. No. 5. México (pp. 11 34). DOI: https://doi.org/10.32870/cys.v0i5.4008

Duby, Georges. (1988). Diálogo sobre la historia. Conversaciones con Guy Lardreau. Primera edición. Alianza Editorial. España.

El Sol de Sinaloa. (1970, enero 8). Editorial. 71 años de servir a México. México. (p. 6).

El Sol de Sinaloa. (1970, febrero 14). Editorial. Cambio de estructuras. México. (p. 6). 
El Sol de Sinaloa. (1970, febrero, 16). Editorial. La guerrilla urbana. México. (p. 6).

El Sol de Sinaloa. (1970, junio, 24). Editorial. Díaz Ordaz y su obra. México. (pp. 5-6).

El Sol de Sinaloa. (1970, marzo, 24). Editorial. Vacuna contra el comunismo. México. (p. 6).

El Sol de Sinaloa. (1971, marzo, 17). Editorial. Pasaportes coreanos. México. (p. 6).

El Sol de Sinaloa. (1973, marzo, 18). Cumpleaños de José García Valseca. México. (p. 1).

El Sol de Sinaloa. (1973, octubre, 2). Los estudiantes se tomaron. México. (p. 1).

El Sol de Sinaloa. (1973, octubre, 29). Denuncian que Fidel Castro apadrina guerrilla. México. (p. 3).

El Sol de Sinaloa. (1973, septiembre, 12). Cuartelazo en Chile, el presidente derrocado, se mató. México. (p. 1).

Fazio, Hugo. (2018). Historia del tiempo presente y presente histórico. Historiografías. Revista de Historia y Teoría. No. 15. España (pp. 22-35).

Fontcuberta, Mar de, y Borrat, Héctor (2006). Periódicos: sistemas complejos, narradores en interacción. Primera edición. Ediciones La Crujía. Argentina.

Gamiño, Rodolfo. (2011). Guerrilla, represión y prensa en la década de los setenta en México. Invisibilidad y olvido. Primera edición. Instituto Mora. México.

Gil, Anderson Paul. (2020). La Cadena García Valseca en México: la empresa periodística que llenó de soles el país, 1941-1972. Letras Históricas. Volumen otoño-invierno, No. 23. México (pp. 167-194).

Guerra, François-Xavier. (2002). Voces del pueblo. Redes de comunicación y orígenes de la opinión en el mundo hispánico (1808-1814). Revista de Indias. Volumen LXII, No. 225. España. (pp. 357-284).

Guillo, Juan Carlos. (2017). Violencia política y opinión pública en la transición: el caso de la Matanza de Atocha. En Cutillas, Ernesto. Convergencia y Transversalidad en Humanidades. Universidad de Alicante. España.

Habermas, Jurgüen. (1985). Historia y crítica de la opinión pública. Primera edición en español. Gustavo Gili. España.

Hernández, Pablo. (2017). Consideración teórica sobre la prensa como fuente historiográfica. Historia y Comunicación Social. Volumen 22, No. 2. España (pp. 465-467). DOI: https://doi.org/10.5209/HICS.57855

Kircher, Mirta. (2005). La prensa escrita: actor social y político, espacio de producción cultural y fuente de información histórica. Revista de Historia. No. 10. Argentina (pp. 115-122).

Llera, Francisco. (1992). Violencia y opinión pública en el País Vasco, 1978-1992. Revista Internacional de Sociología. No. 83. España (pp. 83-111).

Marchesi, Aldo. (2019). Hacer la revolución: Guerrillas latinoamericanas, de los años sesenta a la caída del muro. Primera edición. Siglo XXI Editores. Buenos Aires.

Márquez, Álvaro. (2007). Discurso político, opinión pública y medios de comunicación en Venezuela. Quórum Académico. Volumen 4, No. 2. Venezuela (pp. 11-31).

Monsiváis, Carlos. (2003). A ustedes les consta: Antología de la crónica en México. Segunda edición corregida. ERA. México.

Noelle-Neumann, Elizabeth. (1995). La espiral del silencio. Primera edición en español. Paidós. España.

Ontiveros, Clara Leticia. (2017). El cambio tecnológico en la prensa de Culiacán, del Taller Tradicional a la Era Digital. Tesis de Maestría. Maestría en Historia. Universidad Autónoma de Sinaloa. México.

Ovalle, Camilo (2020). Participación en Represión estatal y movimientos sociales en los años setenta en México del Instituto Nacional de Estudios Históricos de las Revoluciones Mexicanas. Ciudad de México. México. https://www.youtube.com/watch?v $=$ cPZpudcAKOI 
Pettinà, Vanni. (2018). Historia mínima de la Guerra Fría en América Latina. Primera edición. El Colegio de México. México.

Rincón, Irma. (2012). Amanecer y el poder político en Querétaro: una relación compleja, 1951-1962. Tesis de Maestría. Maestría en Estudios Históricos. Universidad Autónoma de Querétaro. México.

Rivas, José René. (2014). El 68 mexicano y su impacto en la prensa escrita. En Valles, Rosa María, González, Rosa María, y Vega, Patricia. La prensa: un actor sempiterno. De la Primera Guerra Mundial a la Posmodernidad. Universidad Autónoma del Estado de Hidalgo. México.

Sampedro, Víctor, y Resina, Jorge. (2010). Opinión pública y democracia deliberativa en la Sociedad Red. Ayer. Revista de Historia Contemporánea. Volumen 80, No. 4. España (pp. 139-162).

Sánchez, Sergio Arturo. (2016). El Sol de Sinaloa y la violencia política en México en el año de 1972. Ciencia Nueva. Revista de Historia y Política. Volumen 1, No. 1. Colombia (pp. 185-209).

Serna, Ana María. (2014). La vida periodística mexicana y el movimiento estudiantil de 1968. Signos Históricos. Volumen 16, No. 31. México (pp. 116-160).

Silva, Renán. (2014). Ciencias sociales e historia. Un balance de las formas de hacer: perspectivas de teoría y de investigación. Revista Co-herencia. Volumen 11, No. 21. Colombia (pp. 25-45).

Talancón, Jaime. (2009). La violencia política. Revista de la Facultad de Derecho. Volumen 59, No. 251. México (pp. 377-388).

Uribe, María Victoria, y Ureña, Juan Felipe. (2019). Miedo al pueblo. Representaciones y autorrepresentaciones de las FARC. Primera edición. Universidad del Rosario. Colombia.

Vásquez, Yair. (2012). La Revista ¿Por qué? Como foro de la izquierda radical en México, 1968-1974. Tesis de Maestría. Maestría en Historia y Etnohistoria. Escuela Nacional de Antropología. México.

Zermeño, Guillermo. (2007). El espacio público como concepto histórico. Habermas y la nueva historia política. En Lemperiere, Annick, y Cárdenas, Elisa. François Xavier Guerra. Una ausencia que convoca. Universidad de Guadalajara. México. 